\title{
EDIOURO: IMPRESSÕES À MARGEM DOS TEXTOS DA LITERATURA ITALIANA TRADUZIDA NO BRASIL
}

\author{
Joseni Terezinha Frainer Pasqualini \\ Silvana de GaSPari ${ }^{*}$
}

RESUMO: No percurso de sua expansão, a Ediouro Publicações distingue-se pela diversidade de atividades, entre as quais a tradução de obras estrangeiras. No que diz respeito a autores italianos, nomes como Dante, Boccaccio, São Francisco, Papini, Salgari e Petrarca constam do catálogo desta editora. Nesta significativa tarefa de traduzir autores e seus escritos, o produto final da obra de chegada encontra-se cercado e prolongado por traços verbais ou não-verbais, elementos à margem do texto, constituintes do paratexto. Nesse sentido, a proposta deste trabalho é analisar elementos paratextuais na tradução realizada por Malba Tahan, do Inferno, da Divina Comédia, e publicada pela Ediouro Publicações.

PALAVRAS-CHAVE: Tradução; literatura italiana; paratexto.

ABSTRACT: Nel suo percorso di espansione, la Ediouro Publicações si distingue per la diversità di attività, tra le quali la traduzione di opere straniere. Per ciò che riguarda gli autori italiani, nomi come quelli di Dante, Boccaccio, San Francesco, Papini, Salgari e Petrarca si trovano nel catalogo di questa casa editrice. Nel difficile lavoro di tradurre, il prodotto finale dell'opera di arrivo viene ampliato da elementi verbali e non verbali, elementi a margine del testo, che costituiscono il paratesto. La proposta di questo lavoro è analizzare elementi paratestuali della traduzione di Malba Tahan dell'Inferno, della Divina Commedia pubblicata dalla Ediouro Publicações.

* Universidade Federal de Santa Catarina, Florianópolis (Brasil) - josenipasqualini@ gmail.com / silvanadegaspari@ gmail.com

Processo n.2013/20971-0 Fundação de Amparo à Pesquisa do Estado de São Paulo (FAPESP)

DOI: http://dx.doi.org/10.11606/issn.2238-8281.v0i33p84-95 
PAROLE CHIAVE: traduzione; letteratura italiana; paratesto.

ABSTRACT: In the course of its expansion, The Ediouro Publications distinguishes itself by the diversity of activities, including the translation of foreign works. With regard to Italian authors, names like Dante, Boccaccio, San Francisco, Papini, Salgari and Petrarch are displayed on the catalog of this book publisher. In this significant task of translating authors and their writings, the final product of the arrival work is surrounded and extended by verbal or nonverbal traits, elements at the margin of the text, which constitute the paratext. In this sense, the purpose of this paper is to analyze the paratextual elements in the translation accomplished by Malba Tahan, the Hell, part of the Divine Comedy.

KEYWORDS: Translation; Italian literature; paratext. 


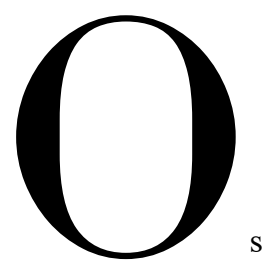

s irmãos porto alegrenses Jorge e Antônio Gertum Carneiro fundam, em 1940, na cidade do Rio de Janeiro, a Ediouro Publicações, um empreendimento ligado à importação de papel vegetal, ao agenciamento de assinaturas de revistas estrangeiras e à comercialização de livros técnico-científicos, vindos dos Estados Unidos da América. Entre os anos de 1943 e 1946, ocorrem significativas transformações na empresa - os sócios adquirem uma gráfica, a Tecnoprint Gráfica S.A. -, o que representou a independência da editora no que se refere à produção de livros, ao número de publicações e às traduções ligadas aos campos técnico-científicos, nas áreas de engenharia, medicina e arquitetura.

Nessa trajetória, e empreendedores que eram, empregam também recursos na edição de material didático, em cadernos com exercícios direcionados a interessados em concursos e cursos colegiais, em traduções de romances policiais, de faroeste, de séries norte-americanas. Intensificam o investimento em traduções de autores estrangeiros, em especial títulos apontados pela editora em questão como "clássicos da literatura universal".

Tais estratégias corresponderam às expectativas dos sócios, pois, enquanto as traduções de livros de medicina e engenharia exigiam grande investimento e não se esgotavam com facilidade, as publicações de formatos diversos, seja de bolso ou não, de obras literárias, a exemplo dos 
"Clássicos de bolso", da coleção "Edições de Ouro", ${ }^{1}$ demandavam constantes reedições.

No que se refere à literatura italiana, constatou-se que a Editora, ${ }^{2}$ entre os anos de $1960 \mathrm{e}$ 2008, editou e reeditou obras de escritores como São Francisco de Assis, considerado primórdio da Literatura Italiana, passando por Dante Alighieri, Giovanni Boccaccio, Francesco Petrarca, Tommaso Campanella, Niccolò Machiavelli, Carlo Goldoni, Giacomo Leopardi, Alessandro Manzoni, até autores mais recentes, a exemplo de Emílio Salgari e Giovanni Papini.

Essas publicações chegam acompanhadas de um conjunto de elementos verbais e nãoverbais, a exemplo do nome do autor, do ilustrador, do título, da dedicatória, do prefácio, do posfácio, de uma entrevista, o que propicia ao texto certa extensão e condução, "[...] exatamente para apresentá-lo, no sentido habitual do verbo, mas também em seu sentido mais forte: para torná-lo presente, para garantir sua presença no mundo, sua recepção e seu consumo, sob a forma, pelo menos hoje, de livro" (GENETTE, 2009, p. 9).

Diante disso, a proposta deste trabalho é a de analisar alguns desses elementos presentes em tradução idealizada por Malba Tahan, da Divina Comédia, do autor italiano Dante Alighieri, publicada pela Editora Ediouro. Para tanto, parte-se das concepções do semiólogo e teórico da literatura francesa Gérard Genette que, na obra Seuils (1987), ${ }^{3}$ apresenta um estudo sistemático sobre elementos, por ele designados de paratextos, os quais cercam e rodeiam um texto.

Genette, ao juntar ao vocábulo "texto"4 o prefixo "para", estabelece uma relação de algo que, mesmo próximo ou distante do texto, também se constitui em texto. Observa, nesses elementos, não uma "fronteira, um limite estanque", mas um limiar, zona indecisa entre o dentro e o fora, que se situa entre o texto e o além-texto, mas sem demarcação precisa, [...] "franja do texto impresso que comanda toda a leitura" (GENETTE, 2009, p. 9), zona de transmissão e transação,

1 Em sua expansão, a empresa adotou as denominações Publicações Pan-Americanas; Editora Gertum Carneiro S. A.; Editora Tecnoprint S. A e Ediouro Publicações.

2 Foi realizada uma pesquisa (2014/15), em Estante Virtual, na Biblioteca Nacional e site da Ediouro, elencando autores e obras da literatura italiana traduzida no Brasil por esta editora. O objetivo seria o de dar continuidade à elaboração do Dicionário da Literatura Italiana Traduzida no Brasil, um projeto idealizado entre duas instituições, a Universidade de São Paulo/USP e a Universidade Federal de Santa Catarina/UFSC.

3 Para este estudo nos valeremos da tradução de Álvaro Faleiros, publicada pela editora Ateliê Editorial, no ano de 2009, com o título Paratextos Editoriais.

$4 \mathrm{O}$ termo texto pode ser entendido em sentido lato, como qualquer tipo de manifestação da textualidade do ser humano, sob qualquer mediação semiótica. No sentido estrito, diz respeito a qualquer passagem, falada ou escrita, que forma um todo significativo, independente de sua extensão. FAVERO, L. L.; KOCH, I. G. V. Linguística Textual: uma introdução. $3^{\circ}$ ed. São Paulo: Cortez, 2009. 
aquilo que inevitavelmente antecede e leva a retroceder diante do texto ou de entrar no texto. Assim,

[...] o paratexto é aquilo por meio de que um texto se torna livro e se propõe como tal a seus leitores, e de maneira mais geral ao público. [...] compõe-se, pois, empiricamente, de um conjunto heteróclito de práticas e de discursos de todos os tipos e de todas as idades que agrupo sob esse termo, em nome de uma comunidade de interesse, ou convergência de efeitos, que me parece mais importante do que a diversidade de aspecto (GENETTE, 2009, p. 9- 10).

São elementos que possuem importante papel de apresentar um texto, assegurando, de certo modo, sua difusão. Pode-se dizer que, aos olhos de quem elabora o paratexto, ele é acolhimento, é convite. Não há dúvida de que os modernos recursos midiáticos tornaram possível a multiplicação de elementos no entorno do texto, de uma maneira pouco comparável ao que acontecia na Antiguidade e na Idade Média, quando os textos circulavam, muitas vezes, quase que em estado bruto.

Contudo, mesmo que os tipos móveis e a prensa tenham transfigurado a relação com a cultura escrita, visto que até meados de 1450, a reprodução de um livro somente se dava pelas mãos do copista, a transformação não foi absoluta. Os manuscritos e, posterior a eles, o livro impresso, ainda apresentam características estruturais muito semelhantes. "Há, portanto, uma continuidade muito forte entre a cultura do manuscrito e a cultura do impresso" (CHARTIER, 2009 , p. 9) e, nesse contexto, é significativa a proposição genettiana de que “[...] não existe, e que jamais existirá, um texto sem paratexto" (GENETTE, 2009, p. 11).

Desse modo, muitos atributos do manuscrito se consolidaram no impresso; o que, de certo modo, diferenciou-se foi a evolução em termos de paratextos. O leitor dos séculos XV e XVI não era beneficiado com tantos elementos que o encorajavam a prosseguir ou não com a leitura. Deveria, por exemplo, folhear parte da obra para encontrar seu registro civil, pois a página de rosto - espaço em que atualmente podem ser depreendidas diversas informações - era ainda inexistente. O texto iniciava "[...] logo no reto da primeira folha, logo após uma breve fórmula na qual é indicado geralmente o assunto da obra e às vezes o nome de seu autor" (FEBVRE; MARTIN, 1982, p. 128). Para obter informações mais amplas, o leitor deveria dirigir-se ao final do volume, no colofão, espaço também existente nos manuscritos, em que estavam inscritos o 
local da impressão, o nome do tipógrafo e, frequentemente, o título exato da obra e o nome de seu autor. Acerca disso, podem-se citar como exemplo as primeiras edições da Divina Comédia, as quais foram impressas quase duas décadas após o surgimento da imprensa e eram, no dizer de Michele Senzini (2012), escassas de aparatos paratextuais.

O ano de 1472 marca a data da primeira impressão, na Itália, da Divina Commedia. Tal trabalho foi realizado pelo tipógrafo Giovanni Numeister, junto a Evangelista Angelini di Trevi, tendo a colaboração de Emiliano Orfini. O manuscrito da Commedia, do qual teria se originado a impressão, foi o Lolliniano 35, manuscrito do século XV, conservado na Biblioteca do Seminário di Belluno (SENZINI, 2012).

Ainda no ano de 1472, outras duas impressões do poema foram editadas em Jesi, pelo tipógrafo Federico de' Conti, e em Mantova, um trabalho realizado por Giorgio e Paolo Teutonici (SENZINI, 2012). Todas são reproduções de manuscritos, dos quais nenhum seria a cópia do manuscrito original de Dante, mas de algum dos cerca de setecentos manuscritos que circulam da Comédia. ${ }^{5}$

Quanto à presença de Dante no Brasil e na literatura brasileira até os três primeiros séculos da chegada dos portugueses, esta pode ser considerada residual, resumindo-se a alguns intelectuais e escritores que, por razões diversas, se aproximam das obras de Dante Alighieri. Será a partir da segunda metade do século XIX que a Divina Comédia, enquanto tradução, começará a figurar no cenário brasileiro.

Há que se ter em mente que, da transição do período colonial para independência, e desta para as ideias abolicionistas e republicanas, eclode, sob a influência europeia, o Romantismo. Um movimento sobretudo de liberdade espiritual, social e política, tempo em que se intensificou o entrecruzamento de autores e obras, das formas literárias, de intensa produção literária e de tradução.

A partir de dados divulgados em artigo intitulado Em busca de Dante em Português no Brasil (1901-1950), de autoria de Maria Teresa Arrigoni (2011), tem-se que Gonçalves Dias, Machado de Assis, D. Pedro II e Luiz Vicente De Simoni envolveram-se na transposição para o português da Divina Comédia, traduzindo especificamente fragmentos de cantos. Além dessas publicações, em 1888, a Imprensa Nacional do Rio de Janeiro lançou a tradução da Divina Comédia realizada por Francisco Bonifácio de Abreu, o Barão da Vila da Barra, a qual representa

5 Segundo Italo Borzi, dos manuscritos da Comédia muitos não são datados; dos que possuem registro "[...] o mais antigo é de 1329-1330, oito anos após a morte do poeta” (BORZI 1996, p. 21). 
a primeira Divina Comédia traduzida na íntegra por um brasileiro e publicada no Brasil. A estas, muitas outras se sucederam.

Já no que se refere à Ediouro, no âmbito das obras de Dante Alighieri, merecem destaque os trabalhos realizados por João Penteado E. Stevenson, Pedro Xavier Pinheiro, Cordélia Dias de Aguiar, Marques Rabelo e Malba Tahan, que perfazem um total de dezenove edições de traduções, das quais três aludem à Da Monarquia e dezesseis à Divina Comédia. Para efeito do presente trabalho, conforme exposto anteriormente, elegemos, dessa editora, a tradução do Inferno da Divina Comédia realizada por Malba Tahan, individuando, para tal análise, a capa e a contracapa ${ }^{6}$ espaços que comportam elementos paratextuais.

$\mathrm{Na}$ capa da tradução em questão, ter-se-ão como elementos considerados paratextuais a ilustração, o nome do autor original, o título, o nome do tradutor, o nome do ilustrador, a coleção à qual pertence esse livro e o nome da editora. Lembrando que o formato da letra, as cores e o projeto gráfico são também, à luz da teoria genettiana, entendidos como paratextos, escolhas editoriais que colaboram para a construção de representações por parte do leitor e do público em geral acerca do texto ou da natureza da leitura.

Retomem-se, aqui, alguns elementos constituintes da capa: Dante, autor da Comédia, Malba Tahan, o tradutor, e Gustave Doré, o ilustrador. Com referência ao nome do autor, importante considerar que, no tocante aos manuscritos antigos ou medievais, estes não possuíam a obrigatoriedade e nem um lugar determinado para a indicação do autor que, por vezes, estava presente nas primeiras ou últimas frases do texto (GENETTE, 2009). Na atualidade, a autoria da obra aparece na folha de rosto e ou na capa e comporta em cada espaço funções distintas:

[...] a primeira é modesta e por assim dizer legal [...] a segunda tem dimensões muito mais variáveis, conforme a notoriedade do autor e, quando as normas de coleção impedem toda e qualquer variação, uma sobrecapa lhe dá campo livre, ou uma cinta permite repeti-lo em caracteres mais chamativos e, por vezes, sem o prenome, para mostrar como é famoso (2009, p. 41).

Maria Teresa Arrigoni aponta a segunda metade do século XIX como época na qual se

6 Os elementos paratextuais, objetos de análise deste trabalho, tanto da capa quanto da contracapa foram todos extraídos do livro: Alighieri, Dante, O Inferno, Tradução em forma de narrativa de Malba Tahan, Editora Tecnoprint $\mathrm{S}$. A., Ediouro, (s. d.), Coleção Universidade de Bolso. 
encontra o registro da mais antiga tradução brasileira da Divina Comédia, a qual "[...] foi publicada em uma antologia de textos italianos traduzidos, organizada por Luís Vicente De Simoni, no ano de 1843" (ARRIGONI, 2011, p. 44). Em pesquisa no Dicionário Bibliográfico da Literatura Italiana Traduzida no Brasil, encontramos registradas, até 1950, quinze traduções da Divina Comédia. São trabalhos realizados, quer em forma de narrativa e ou adaptações, edições completas, cantos ou fragmentos de cantos.

Isso implica inferir que, quando a Ediouro iniciou seu processo de tradução de literatura italiana, por volta de 1960, o poeta florentino Dante Alighieri já figurava no cenário literário brasileiro. Tal caso justifica a assertiva de Genette de que "[...] quanto mais o autor é conhecido mais é exibido" (GENETTE, 2009, p. 40). O mesmo pode ser estendido ao ilustrador, Gustave Dorè, conhecido pelas ilustrações atribuídas à Comédia de Dante, que circulam no Brasil desde 1917.

Quanto ao nome do tradutor, que também aparece na capa, há que se considerar que, no Brasil, a Lei 9610/98 passou a garantir a obrigatoriedade de constar na obra o nome de quem a traduz. Os procedimentos de registro da Biblioteca Nacional estipulam que o nome do tradutor deverá constar na ficha catalográfica. A Ediouro opta por anunciá-lo já na capa. Talvez tal postura advenha do fato de Malba Tahan ser, à época, escritor conhecido por inúmeras obras publicadas. Malba Tahan é um dos pseudônimos adotados por Júlio Cesar de Mello e Souza.?

Na capa, os três nomes aparecem destacados: autor, tradutor e ilustrador. Certo dizer-se que o nome Dante aparece evidenciado, ficando bem próximo ao título, o que é dado pela cor e pelo tamanho da letra empregados. Contudo, não se poderia deixar de observar que o ilustrador e o tradutor também foram enfatizados, atitude que poderia ser adotada tanto para dar a conhecer como para sublinhar figuras já conhecidas no cenário literário, pelo leitor e pelo público. ${ }^{8}$

Ainda na constituição da capa, tem-se também o título $O$ Inferno. Nos elementos paratextuais analisados, não encontramos informação pontual de que o Inferno está vinculado à Divina

7 Júlio Cesar de Mello e Souza nasceu na cidade do Rio de Janeiro, em 1895. Adotou o pseudônimo Malba Tahan como tradutor e como escritor. Uma das suas publicações foi o livro intitulado O Homem que Calculava, lançado em 1938. 8 Genette (2009) diferencia público de leitor: o público seria aquele que entra em contato com elementos paratextuais e poderia lê-los integralmente ou parcialmente. Geralmente, esses elementos encontram-se na quarta capa, nas orelhas e possuem características do discurso publicitário. Já o leitor, no entender do estudioso, seria aquele que não somente lê o que está no entorno, próximo ou distante do livro, mas o livro na íntegra. 
Comédia. ${ }^{9}$ Tal fato poderia causar a compreensão, para o público, de que Dante Alighieri teria escrito somente a obra intitulada $O$ Inferno. Ao atribuir equivocadamente ao Inferno o valor total da obra, estará a Editora restringindo a Divina Comédia aos cantos do Inferno.

Destaque-se, outrossim, que a coleção da qual faz parte esta tradução é denominada de Coleção Universidade de Bolso, o que aparece na capa e na contracapa. Nesta última, logo abaixo da indicação, tem-se a informação no que consiste a coleção de bolso: "Os melhores clássicos da literatura universal, a preços acessíveis e formatos convenientes que além de leves e portáteis cabem no bolso de um paletó ou na bolsa de uma mulher".

O projeto encampado pela Ediouro, de levar ao leitor livros com brochuras baratas e em tamanho reduzido, conhecidos como livros de bolso, teve início na década de 50. Laurence Hallewell observa que, no Brasil, não somente a Ediouro, mas outras editoras investiram em livros de bolso e que “[...] todos os títulos são reimpressões, com o simples propósito de expandir o mercado para os bons livros já disponíveis em edições normais”(2005, p. 673).

Seguida da explicitação sobre o formato do livro, tem-se, ainda, na contracapa: "Como as demais coleções, a nossa preocupação é oferecer uma leitura agradável e, ao mesmo tempo, de utilidade para estudantes e professores". Subentende-se, então, que a editora, de certo modo, limita o público a que se destina o livro - estudantes e professores. Editar obras para o universo escolar vai ao encontro dos propósitos advindos da política de governo da década de sessenta, que propagou a ampliação do ensino brasileiro em todos os níveis. Nessa configuração, no dizer de Labanca (2009), os resultados da Ediouro foram considerados positivos. Os investimentos idealizados para este público tiveram retorno garantido.

Na sequência do texto da contracapa, a Ediouro afirma: "Para isso (a função de oferecer uma leitura agradável e ao mesmo tempo utilitária) contamos com a colaboração de mestres da literatura nacional, que, além das traduções impecáveis, elaboram prefácios, guias para o leitor e biografia dos autores". Pelos dizeres apresentados, poder-se-ia evidenciar certa preocupação da editora em disponibilizar aos leitores brasileiros obras da literatura universal, ao mesmo tempo resolvida com a contratação dos serviços de "mestres da literatura nacional". A editora reporta-se ao trabalho dos tradutores pela sua habilidade em verter uma obra de uma língua a outra e pela capacidade de elaborar "traduções impecáveis" e "prefácios, guias para o leitor e

9 A Divina Comédia dantesca é composta de cem cantos, os quais relatam uma viagem pelos três reinos do outro mundo: o Inferno, o Purgatório e o Paraíso. 
a biografia dos autores".

Importante destacar-se que o tradutor, no percurso de seu trabalho, manipula e reinterpreta o texto original, com vistas a um objetivo maior, o leitor. Contudo, não só as escolhas do que traduzir, mas também as estratégias estabelecidas são por vezes mediadas por parte da editora e acabam por garantir à figura do tradutor certa visibilidade ou sua invisibilidade. A visibilidade é defendida por diversos estudiosos da tradução, a exemplo de Lawrence Venuti, o qual entende que o processo inverso - a invisibilidade - está por vezes relacionado ao parco reconhecimento do trabalho do tradutor, em função da exploração econômica, corroborando o autoaniquilamento do tradutor.

Outro trecho da contracapa alude à tarefa de ler Dante no original:

Ler Dante no original é, para um brasileiro, tarefa quase que impossível; por outro lado, em nada adiantaria, para aquele que quisesse sentir e admirar toda a beleza da Comédia conhecer o sacro Poema através de simples tradução. Que fez então Malba Tahan para contornar esse óbice? Elaborou, para a Divina Comédia, uma tradução sob a forma de narrativa, intercalando no próprio texto dessa narrativa os versos mais famosos e as estrofes mais expressivas que o leitor deve ler e conhecer no original.

O fato de o texto indicar impossibilidade em "conhecer o sacro Poema" de Dante poderia distanciar, de certo modo, o leitor de um contato com a forma estética primeira, a poesia dantesca. Assim sendo, induzido por essa subentendida incapacidade, o leitor seria condicionado à leitura dessa obra modificada em uma versão sob a forma de narrativa.

Outra informação contida no trecho é a de que a narrativa intercala "os versos mais famosos e as estrofes mais expressivas que o leitor deve ler e conhecer no original". Isto posto, poderiam surgir certos questionamentos, a exemplo de como foi realizada a escolha dos versos, quais os critérios estabelecidos para a seleção do que deveria ser publicado e o que encerra o caráter da fama e da expressividade dos versos e das estrofes. Além disso, tem-se que "Pela leitura dessa atraente e invulgar tradução, e pela análise meditada dos interessantes e eruditos comentários que acompanham os diversos cantos, ficará o dantófilo conhecendo, de modo completo e perfeito [grifo nosso] a obra prima da Literatura Universal. 
Esse texto transcrito na contracapa ${ }^{10}$ encontra-se também no interior do livro. Genette aponta que a função e o lugar de cada elemento paratextual não são de ordem alternativa e excludente, mas podem, sim, possuir variados fins, sem que um deva necessariamente rejeitar o outro. Mais do que isso, os elementos paratextuais podem ser emitidos pelo autor ou escritos por alguém que não o autor (alógrafos) e endereçados a destinatários diferentes.

No interior do livro, o mesmo texto da contracapa assume uma função prefacial. Genette sublinha a importância do prefácio ao dizer que ele se propõe a "[...] deter a atenção do leitor para ler o livro, e para a leitura bem-sucedida, ideias ligadas ao porquê ler a obra e como lê-la" (GENETTE, 2009, p. 176). Desse modo, o autor original, ao prefaciar seu livro, tende a valorizar o texto, elogiando-se. Investe na forma e em como o assunto foi tratado, significando, na maioria das vezes, uma "[...] maneira mais segura de prevenir as críticas, isto é, de neutralizá-las ou mesmo de impedi-las, tomando a dianteira” (2009, p.187).

Ainda no dizer de Genette, esse fazer advém de uma prática retórica antiga e que, de certa forma, a partir do século XIX, foi substituída pela encomenda de prefácios, poupando o autor da posição incômoda de se autoelogiar. O trecho, objeto de análise, comporta um misto de elogio e escusa. Vale lembrar que se trata de obra traduzida. Genette, em seu estudo, não se atém a paratextos de obras traduzidas, entretanto, o que aponta parece pertinente, dizendo de outro modo, cabe perfeitamente para textos traduzidos.

Correlato à ideia de paratexto, há que se considerar o que sublinha Michel Foucault:

[...] as margens de um livro jamais são nítidas nem rigorosamente determinadas: além do título, das primeiras linhas e do ponto final, além de sua configuração interna e da forma que lhe dá autonomia, ele está preso em um sistema de remissões a outros livros, outros textos, outras frases: nó em uma rede [...] A constituição de uma obra completa ou de um opus supõe um certo número de escolhas difíceis de serem justificadas ou mesmo formuladas (FOUCAULT, 2008, p. 26).

A partir do exposto, no movimento do texto - de sua passagem do espaço privado ao público

10 Durante a presente pesquisa, encontramos catalogado no Dicionário Bibliográfico da Literatura Italiana Traduzida até 1950 um livro com o mesmo título (O Inferno), mesmo tradutor (Malba Tahan) e semelhantes elementos paratextuais, na contracapa e em parte do prefácio. A referida obra foi publicada pela Gráfica Editora Aurora, da cidade do Rio de Janeiro, em 1947. Informação disponível em <http://www.dlit.ufsc.br>Acesso em: out/2015. 
e, então, tornar-se um livro impresso -, ocorre um processo que culminará com sua ampliação. Genette indica que os elementos constitutivos do paratexto, unidos ao texto principal, envolvem, prolongam e compõem a obra como um todo, cuja função é a de modular o texto, cuidar de sua recepção e orientar sua leitura.

Depreende-se que aquilo que está dentro ou fora, à margem, o modo como a Ediouro apresenta esta tradução, poderá soar como estratégia do contexto mercadológico. Mas significa também espaço de divulgação de uma obra e de seu autor e, neste caso, da literatura italiana traduzida no Brasil. Fiquemos, no entanto, com o alerta de Genette (2009, p. 360): “Atenção ao paratexto!".

\section{Referências}

ARRIGONI, Maria Teresa. Em busca das obras de Dante em Português no Brasil (1901 - 1950). In: PETERLE, Patrícia. A literatura italiana no Brasil e a literatura brasileira na Itália: sob o olhar da tradução. Tubarão: Copiart, 2011, pp. 43 - 60.

BORZI, Italo. [Introduzione a] La Divina Commedia: Introduzione di Italo Borzi, commento a cura di Giovanni Fallani e Silvio Zennaro. Milano: Biblioteca Economica Newton, 1996, pp.21-30.

CHARTIER, Roger. A aventura do livro: do leitor ao navegador: conversações com Jean Lebrun. Trad. Reginaldo Carmello Côrrea de Moraes. São Paulo, Imprensa Oficial do Estado de São Paulo: Editora UNESP, 2009.

FEBVRE, Lucien; MARTIN, Henri-Jean. O aparecimento do livro. Trads. Fulvia M. L. Moretto, Guacira Marcondes Machado. São Paulo: Editora Universidade Estadual Paulista; Hucitec, 1992.

FOUCAULT, Michel, A arqueologia do saber, Trad. Luiz Felipe Baeta Neves,7ed. Rio de Janeiro: Forense Universitária, 2008.

GENETTE, Gérard. Paratextos editoriais. Trad. Álvaro Faleiros. São Paulo: Ateliê Editorial, 2009.

HALLEWELL, Laurence. O livro no Brasil: sua história. Trad. Maria da Penha Villalobos, Lólio Lourenço de Oliveira e Geraldo Gerson de Souza. São Paulo: Edusp, 2005.

LABANCA, Gabriel Costa, Publicações Pan-Americanas e Editora Gertum Carneiro: dos livros técnicos às edições de bolso. In: II Seminário Brasileiro Livro e História Editorial, 2009. Disponível em: <http://www.academia.edu>. Acesso: 16/maio/2014.

SENSINI, Michele. L'edizione commentata della Divina Commedia di G.A. Scartazzini: un modello nella tradizione dei commenti danteschi. 2012. Ein Dienst der ETH-Bibliothek ETH Zürich, Rämistrasse 101, 8092 Zürich, Schweiz. Disponível em: <www.library.ethz.ch>. Acesso em 13 de maio de 2016. pp.40-63.

VENUTI, Lawrence, A invisibilidade do tradutor. Trad. Carolina Afaro. Rio de Janeiro: Grypho, 1995.

Recebido em 22/12/2016

Aprovado em 12/05/2017 